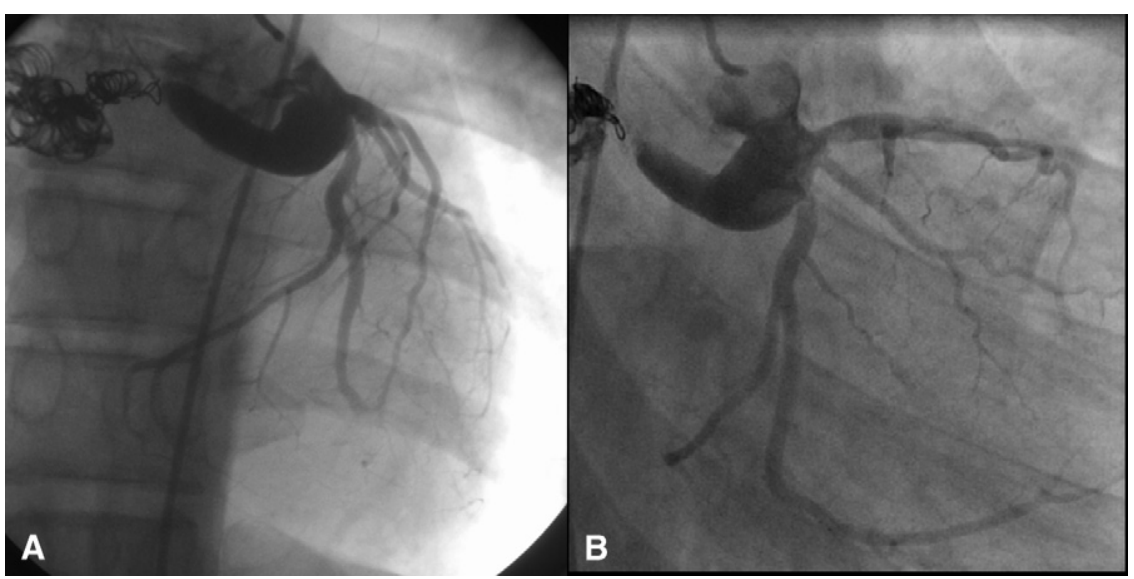

FIGURE 2. A, Cardiac catheterization shows the previously placed coils and the aneurysmal left main coronary artery. B, Also visible are filling defects in all proximal 3 branches of the left main coronary artery, which represent thrombus.

All large or symptomatic CAFs should be closed either operatively or percutaneously. ${ }^{4}$ Small, asymptomatic CAFs can be monitored with serial echocardiograms every 3 to 5 years. ${ }^{4}$

Closure has classically involved ligation of the CAF, with or without cardiopulmonary bypass, with low morbidity and mortality. ${ }^{1,2}$ For larger, more complex CAFs, fistula takedown may involve primary repair, pledgeted closure, or coronary artery bypass grafting. Alternatively, transcatheter closure can be used in select cases of CAF. ${ }^{5}$ Although no standardized selection criteria exist; clinically significant CAF, multiple CAFs, CAFs in close proximity to other major coronary arteries, and associated complex heart disease requiring surgery may prohibit transcatheter closure.

\section{CONCLUSIONS}

We report the successful treatment of a man with a left main CAF. CAFs are rare congenital coronary anomalies.
Although predominantly asymptomatic, they can result in significant sequelae, including myocardial infarction. Surgical repair continues to be the criterion standard in the management of CAF, although percutaneous technology has evolved into a viable alternative in select cases.

\section{References}

1. Cheung DLC, Au WK, Cheung HH, Chiu CS, Lee WT. Coronary artery fistulas: long-term results of surgical correction. Ann Thorac Surg. 2001;71:190-5.

2. Lowe JE, Oldham HN Jr, Sabiston DC Jr. Surgical management of congenital coronary artery fistulas. Ann Surg. 1981;194:373-80.

3. Sherwood MG, Rockenmacher S, Colan SD, Geva T. Prognostic significance of clinically silent coronary artery fistulas. Am J Cardiol. 1999;83:407-11.

4. Warnes CA, Williams RG, Bashore TM, Child JS, Connolly HM, Dearani JA, et al. ACC/AHA 2008 Guidelines for the Management of Adults with Congenital Heart Disease: a report of the American College of Cardiology/American Heart Association Task Force on Practice Guidelines (writing committee to develop guidelines on the management of adults with congenital heart disease). Circulation. 2008;118:e714-833.

5. Valente AM, Lock JE, Gauvreau K, Rodriguez-Huertas E, Joyce C, Armsby L, et al. Predictors of long term adverse outcomes in patients with congenital coronary artery fistulae. Circ Cardiovasc Interv. 2010;3:134-9.

\title{
Video-assisted thoracoscopic surgical lobectomy with limited en bloc resection of superior sulcus tumor
}

\author{
Ivan H. W. Cheung, MBBS, BEng, ${ }^{\text {a } a n d ~ E r i c ~ L i m, ~ M D, ~ M B, ~ C h B, ~ M S c, ~ F R C S(C-T h), ~}{ }^{\text {a,b }}$ London, \\ United Kingdom
}

\footnotetext{
From the Imperial College School of Medicine, ${ }^{a}$ London, United Kingdom; and the Academic Division of Thoracic Surgery, ${ }^{\mathrm{b}}$ Royal Brompton Hospital, London, United Kingdom.

Disclosures: Authors have nothing to disclose with regard to commercial support.

Received for publication July 10, 2012; revisions received Aug 19, 2012; accepted for publication Sept 12, 2012; available ahead of print Oct 5, 2012.

Address for reprints: Eric Lim, MD, MB, ChB, MSc, FRCS(C-Th), Imperial College and The Academic Division of Thoracic Surgery, Royal Brompton Hospital, Sydney St, London SW3 6NP, UK (E-mail: e.lim@rbht.nhs.uk).

J Thorac Cardiovasc Surg 2012;144:e148-51

0022-5223/\$36.00

Copyright (C) 2012 by The American Association for Thoracic Surgery

http://dx.doi.org/10.1016/j.jtcvs.2012.09.017
}

A superior sulcus tumor arises from the recess of the pulmonary superior sulci and often extends beyond the lung to invade the structures within the thoracic inlet. Pearson and colleagues ${ }^{1}$ defined a superior sulcus tumor as any apical tumor with associated pain around the shoulder and extending down into the arm. This type of non-small cell carcinoma represents fewer than $5 \%$ of all lung cancers and can be subdivided according to the anatomic position at the apex: the posteriorly located tumors (such as the classic Pancoast 

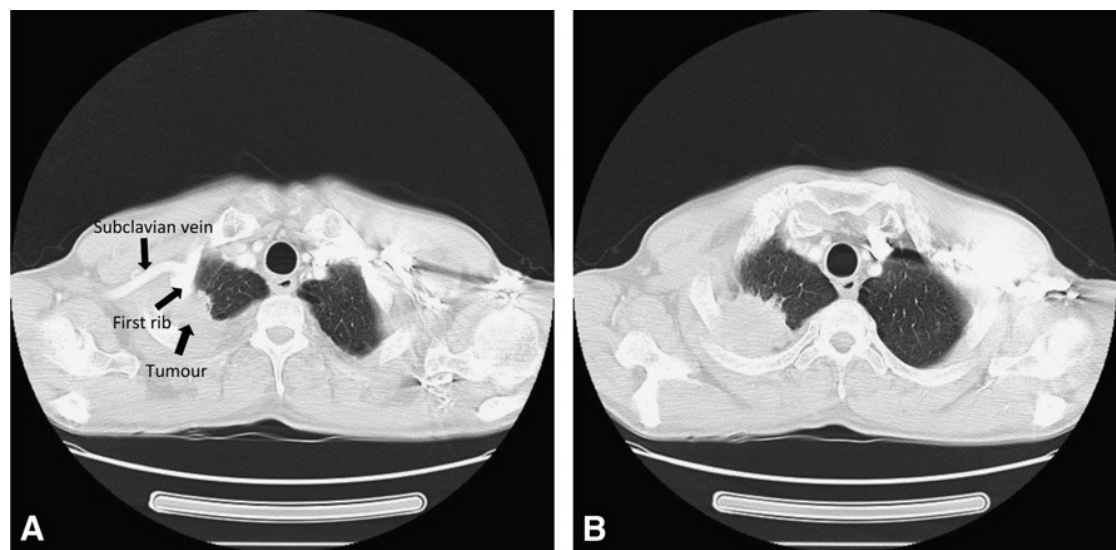

FIGURE 1. A, Apical extent of tumor, illustrating the position of the tumor directly adjacent to the first rib. B, Main tumor body.

tumors with involvement of the first rib accompanied by typical signs and symptoms such as pain, weakness and numbing of the arm, chest pain, and Horner syndrome) and the anteriorly located superior sulcus tumors that can involve the subclavian vessels.

Different surgical approaches have been implemented to optimize resection, but these are traditionally associated with the largest incisions in the textbooks. For posteriorly located tumors, the Paulson posterolateral-paravertebral thoracotomy approach ${ }^{2}$ has been advocated, which involves an incision that extends from the back of the neck, down the side of the vertebrae, and across the back chest wall; for anterior tumors, the anterocervical approach is advocated, which involves an incision down the front of the neck, through the sternum, and across the front chest wall (with or without dislocation of the clavicle). ${ }^{3-4}$

There has been limited use of video-assisted thoracoscopic surgery (VATS) as a management strategy for superior sulcus tumors. Conventionally, VATS lobectomy is indicated for tumors that are peripheral and smaller than 5 $\mathrm{cm}$. The magnitude of any benefit relative to thoracotomy is likely to be small. Paradoxically, we argue the potential benefit of VATS lobectomy is likely to be much more significant in patients that require large incisions.
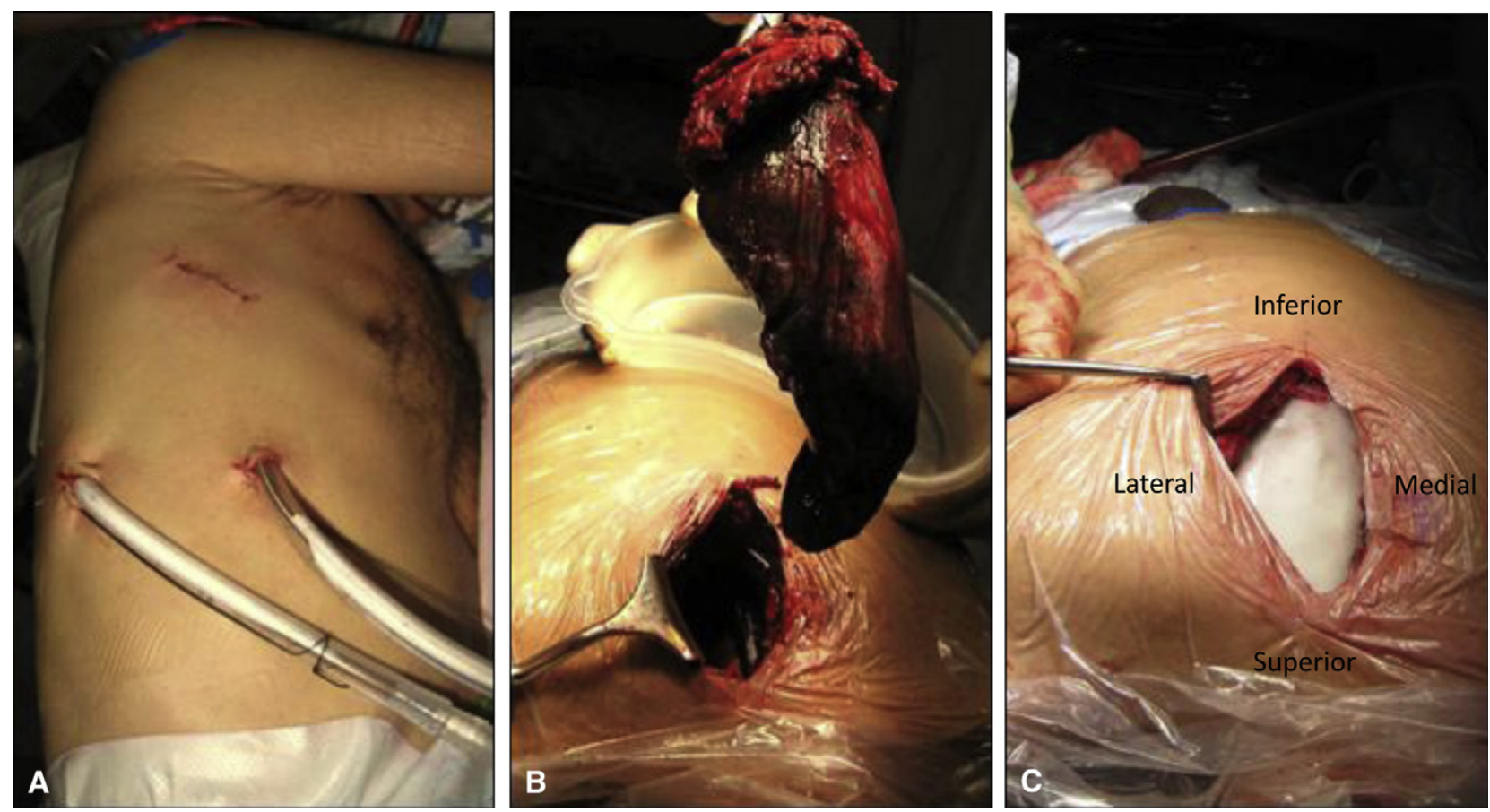

FIGURE 2. A, Video-assisted thoracoscopic surgical lobectomy of the right upper lobe. B, Chest wall en bloc removal of tumor. C, Reconstruction of chest wall. 


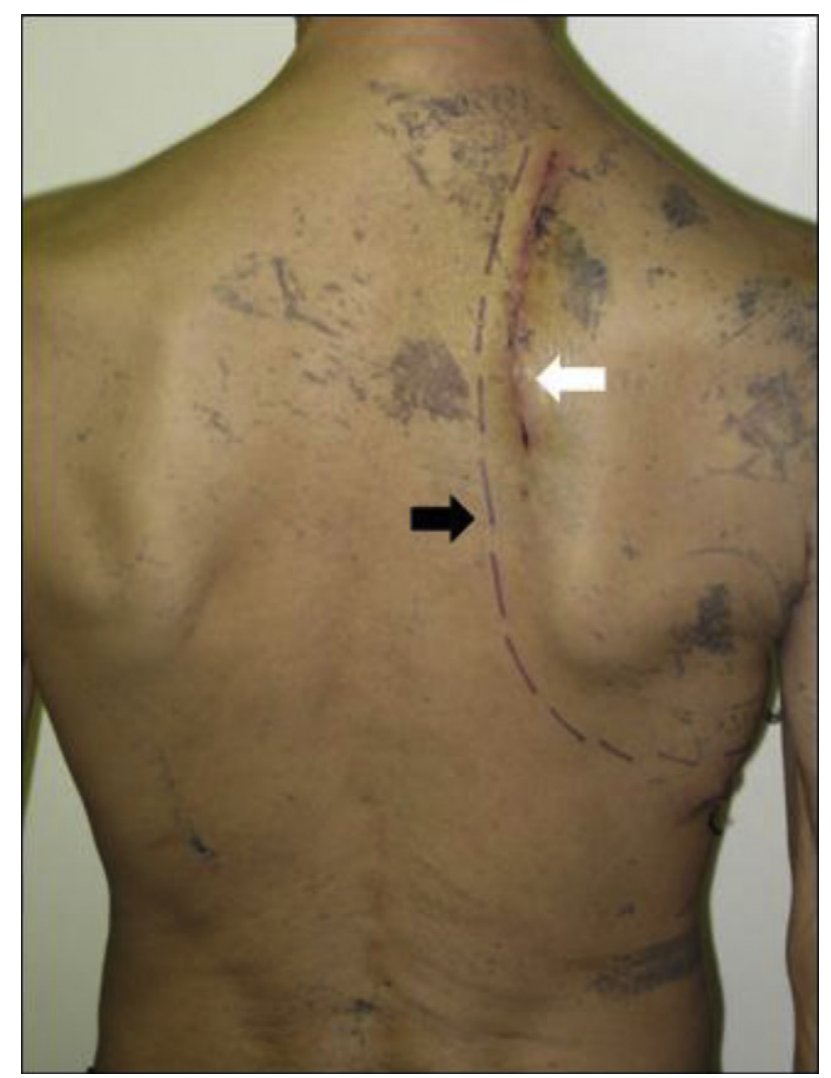

FIGURE 3. Posterolateral-paravertebral approach markings (black arrow) and limited chest wall incision scar for en bloc tumor removal (white arrow).

\section{CLINICAL SUMMARY}

A 54-year-old man was referred for surgical management after the diagnosis of a right superior sulcus tumor with evidence of chest wall involvement. The patient presented with right-sided back pain and pain in the $\mathrm{T} 2$ dermatomal region. He had a 40 pack-year smoking history and no other significant medical history. A number of workup imaging modalities had been performed, which included chest radiography (which showed right upper lobe opacity), computed tomographic scan (which showed a $5.2 \times 3.8 \mathrm{~cm}$ spiculated mass in the right upper lobe abutting the pleural margin; Figure 1), positron emission tomographic scan (which showed an intense activity mass in the apical right lung), and magnetic resonance imaging scan (which showed a $5.0 \times 5.0 \times 4.5 \mathrm{~cm}$ mass lesion in the posterior right lung apex extending through the pleura into the chest wall, with no great vessel or nerve involvement). The final preoperative staging was cT3 N0 M0, with a forced expiratory volume in 1 second of $2.67 \mathrm{~L}$ and a forced vital capacity of $4.27 \mathrm{~L}$.

The operation began with a VATS procedure, and 3 right VATS incisions were initiated. On entering the cavity, the lung tumor was visible at the posterior right apex and in continuum with the chest wall between ribs 2 to 4 . The right upper lobe was resected by the Hansen method, ${ }^{5}$ specifically the placement of a small utility incision $(3-5 \mathrm{~cm}$; Figure $2, A$ ), a camera port, and a third working incision. In this case, the utility incision could be even smaller than usual, because the delivery of the tumor would be en bloc with the chest wall. Surgery proceeded from anterior to posterior, starting with the superior vein, which was taken with a surgical stapler (Tri-Stapler; Covidien plc, Dublin, Ireland), followed by the individual branches of the pulmonary artery, the horizontal fissure, the upper lobe bronchus, and finally completion of the posterior aspect of the oblique fissure. The tumor in this case resulted in the lung being nicely splinted (retracted) naturally as a result of the chest wall invasion. The lung and tumor were allowed to remain adherent to the chest wall. The thoracoscope was then used to map the internal chest wall border of the tumor with 18-gauge needles inserted externally to determine the exact position and length required for the external incision. The utility port was sutured, and a chest drain was placed in each of the inferior VATS port sites (Figure 2,A). A limited posterior chest wall resection of ribs 2 to 4 was undertaken, and the lung and tumor were delivered en bloc with the chest wall (Figure 2, B). The reconstruction of the chest wall constituted Prolene mesh (Ethicon, Inc, Somerville, $\mathrm{NJ}$ ) and methylmethacrylate cement (Figure 2, C).

The removed right upper lobe tumor measured $6.7 \times 5.5 \times 5.0 \mathrm{~cm}$. The histologic report showed pathologic staging of pT3 N0 M0 with poorly differentiated adenocarcinoma. The resection margins were clear by a minimum of $4 \mathrm{~mm}$. The postoperative period was uneventful, and the minimal pain present was controlled. The patient was fit for discharge 4 days after the surgery with well healing wounds (Figure 3 ).

\section{DISCUSSION}

Superior sulcus tumor invasion may involve the subclavian vessels, brachial plexus, and vertebrae. Conventionally, large anterocervical or posterolateral-paravertebral incisions have been used for increasing visual exposure and allowing safe resection of these structures. In this report, we highlight the use of VATS as a novel management strategy for posterior superior sulcus tumor without the need for extended thoracotomy. We fully acknowledge that this case does not represent a Pancoast tumor, in that we managed to resect the tumor off $\mathrm{T} 1$ rather than having to resect $\mathrm{T} 1$; we actually consider this to be a high posterior tumor with chest wall invasion. The access to T1 was achieved (see Figure 1, A), however, with the limited access representing the only required extent of the most apical aspect of an extended posterolateral thoracotomy. For anteriorly located tumors, once a VATS lobectomy is undertaken, it is conceivable that a limited neck incision could be used to complete the surgery (including 
vascular reconstruction) at the anterior aspect of the apical thoracic cavity.

Additional advantages include the ability to assess the tumor invasion extent from within the thoracic cavity to allow internal mapping and much more accurate placement of a subsequent external incision for chest wall resection. Furthermore, the hilum in such cases is usually normal, and the natural apical retraction of the lung from the apical chest wall invasion facilitates VATS lobectomy.

VATS as a surgical option for superior sulcus tumors has previously been reported with good results, ${ }^{6,7}$ The use of VATS offers the advantage of less postoperative pain, a quicker recovery period, and an improved cosmetic appearance for the patient.

In summary, we put forward an argument for the greater evaluation of "minimal access" VATS surgery for more advanced lung cancer resections and illustrate our position with an example of resection of a superior sulcus tumor, VATS lobectomy, and an accompanying smaller targeted incision to achieve en bloc resection, minimizing the extent of the traditional extended thoracotomy or disarticulation of joints and sternotomy.

\section{References}

1. Pearson FG, Cooper JD, Deslauriers J, Ginsberg RJ, Hiebert CA, Patterson GA, et al. Thoracic surgery. 2nd ed. Philadelphia: Churchill Livingstone; 2002.

2. Shaw RR, Paulson DL, Kee JL. Treatment of superior sulcus tumor by irradiation followed by resection. Ann Surg. 1961;154:29-40.

3. Dartevelle PG, Chapelier AR, Macchiarini P, Lenot B, Cerrina J, Ladurie FL, et al. Anterior transcervical-thoracic approach for radical resection of lung tumors invading the thoracic inlet. J Thorac Cardiovasc Surg. 1993;105:1025-34.

4. Grunenwald D, Spaggiari L, Girard P, Baldeyrou P. Transmanubrial approach to the thoracic inlet. J Thorac Cardiovasc Surg. 1997;113:958-9; author reply 960-1

5. Hansen HJ, Petersen RH, Christensen M. Video-assisted thoracoscopic surgery (VATS) lobectomy using a standardized anterior approach. Surg Endosc. 2011; 25:1263-9.

6. Caronia FP, Ruffini E, Lo Monte AI. The use of video-assisted thoracic surgery in the management of Pancoast tumors. Interact Cardiovasc Thorac Surg. 2010;11: 721-6.

7. Linden PA. Video-assisted anterior approach to Pancoast tumors. J Thorac Cardiovasc Surg. 2010;140:e38-9.

\title{
Successful repair of aortic valve perforation in pediatric Libman-Sacks endocarditis
}

\author{
Lisa C. A. D'Alessandro, MD, ${ }^{\mathrm{a}}$ Stephen M. Paridon, MD, ${ }^{\mathrm{a}}$ and J. William Gaynor, MD, ${ }^{\mathrm{b}}$ Philadelphia, Pa
}

Libman-Sacks endocarditis, a complication of systemic lupus erythematosus, has a predisposition for the mitral and aortic valves and is associated with disease duration, activity, anticardiolipin antibodies, and antiphospholipid syndrome. ${ }^{1,2}$ We describe the successful repair of a large aortic valve perforation secondary to Libman-Sacks endocarditis in a pediatric patient.

\section{CLINICAL SUMMARY}

A 12-year-old boy with an 8-year history of systemic lupus erythematosus presented for evaluation of a new murmur. His course was notable for active disease, Sjögren syndrome, and anticoagulant and anticardiolipin antibodies without thrombotic events. Previous hospitalization 2 years

\footnotetext{
From the Divisions of Cardiology ${ }^{\mathrm{a}}$ and Cardiothoracic Surgery, ${ }^{\mathrm{b}}$ The Children's Hospital of Philadelphia, Philadelphia, Pa.

Disclosures: Authors have nothing to disclose with regard to commercial support.

Received for publication July 25, 2012; revisions received Sept 6, 2012; accepted for publication Sept 13, 2012; available ahead of print Oct 8, 2012.

Address for reprints: Lisa C. A. D'Alessandro, MD, Division of Cardiology, The Hospital for Sick Children, 555 University Ave, Toronto, Ontario, Canada M5G1X8 (E-mail: lisac.dalessandro@sickkids.ca).

J Thorac Cardiovasc Surg 2012;144:e151-3

$0022-5223 / \$ 36.00$

Copyright (c) 2012 by The American Association for Thoracic Surgery

http://dx.doi.org/10.1016/j.jtcvs.2012.09.034
}

earlier demonstrated a normal cardiac examination and echocardiogram.

Examination showed an active precordium, normal heart sounds, mild tachycardia, and mild systolic hypertension with a wide pulse pressure. There was both a grade III/VI low-frequency systolic ejection murmur and a II/IV highfrequency diastolic murmur at the left upper sternal border. Pulses were equal centrally and peripherally with no edema, clubbing, or nail bed changes.

Echocardiography demonstrated moderate to severe aortic insufficiency (AI) arising from a perforation in the noncoronary cusp of the aortic valve, measuring at least 2.3 $\mathrm{mm}$ (Figure 1,A) with early diastolic flow reversal in the abdominal aorta. The left ventricular end-diastolic dimension was $5 \mathrm{~cm}(z=2.91)$ (Figure $1, B)$ with an ejection fraction of $64 \%$. There was mild mitral regurgitation and possibly a small vegetation on the anterior leaflet of the mitral valve.

There was no history of fevers, weight loss, or systemic symptoms to suggest bacterial endocarditis. White blood cell count (maximum $13.3 \times 10^{3}$ cells $/ \mu \mathrm{L}$ ) and C-reactive protein (maximum $0.8 \mathrm{mg} / \mathrm{dL}$ ) were normal with an elevated erythrocyte sedimentation rate $(83 \mathrm{~mm} / \mathrm{h})$, consistent with autoimmune endocarditis. Large-volume blood cultures were negative. 